\title{
Coordinated Exploration for Grand Challenges The Role of Advocacy Groups in Search Consortia
}

\author{
Ørding Olsen, Anders; Sofka, Wolfgang; Grimpe, Christoph
}

Document Version

Final published version

Published in:

Academy of Management Journal

DOI:

10.5465/amj.2015.0730

Publication date:

2016

License

Unspecified

Citation for published version (APA):

Ørding Olsen, A., Sofka, W., \& Grimpe, C. (2016). Coordinated Exploration for Grand Challenges: The Role of Advocacy Groups in Search Consortia. Academy of Management Journal, 59(6), 2232-2255.

https://doi.org/10.5465/amj.2015.0730

Link to publication in CBS Research Portal

\section{General rights}

Copyright and moral rights for the publications made accessible in the public portal are retained by the authors and/or other copyright owners and it is a condition of accessing publications that users recognise and abide by the legal requirements associated with these rights.

Take down policy

If you believe that this document breaches copyright please contact us (research.lib@cbs.dk) providing details, and we will remove access to the work immediately and investigate your claim. 


\section{Coordinated Exploration for Grand Challenges: The Role of Advocacy Groups in Search Consortia}

\section{Anders Ording Olsen, Wolfgang Sofka, and Christoph Grimpe}

Journal article (Final published version)

CITE: Coordinated Exploration for Grand Challenges : The Role of Advocacy Groups in Search Consortia. / Ording Olsen, Anders; Sofka, Wolfgang; Grimpe, Christoph. In: Academy of Management Journa/, Vol. 59, №. 6, 12.2016, p. 2232-2255.

DOI: $\underline{10.5465 / a m j .2015 .0730}$

Uploaded to Research@CBS: January २०18 


\title{
COORDINATED EXPLORATION FOR GRAND CHALLENGES: THE ROLE OF ADVOCACY GROUPS IN SEARCH CONSORTIA
}

\author{
ANDERS ØRDING OLSEN \\ WOLFGANG SOFKA \\ CHRISTOPH GRIMPE \\ Copenhagen Business School
}

\begin{abstract}
Grand challenges are among the most complex problems for modern societies. Many governments and foundations provide substantial resources to encourage the search for solutions. Due to the significance of these problems, organizations often form partnerships in what we call search consortia to engage in joint search and compete for funding. Prior research on joint search highlights the role of specialized organizations, mainly regarding technological domains, to identify a superior solution. However, stakeholder theory leads us to believe that the success of any solution depends on the acceptance and support of important stakeholders. In this study, we suggest that search consortia are more likely to receive funding when they include representatives of stakeholder concerns, so-called advocacy groups. We extend theory on coordinated exploration in joint search by integrating mechanisms from stakeholder theory and argue that advocacy groups improve the generation of potential solutions and provide legitimacy. We test our theory with a unique dataset of 35,249 consortia that proposed solutions to 2,349 grand challenge problems as part of a large European funding program. Our results show that advocacy groups benefit search consortia, particularly when consortia exhibit a high dispersion of technological knowledge and when they are inexperienced.
\end{abstract}

COPD, or chronic obstructive pulmonary disease, makes it hard to breathe, causes disability, and is the third leading cause of death in the United States. Millions of people worldwide are affected by the disease, many of them without knowing. Significant research effort has sparked new ideas about treatments, but they require accurate mapping of the progression of the disease and detection of small, but clinically relevant changes. In 2009, the Innovative Medicines Initiative decided to provide funding for a five-year project that involved 19 organizations, among those Glaxo-SmithKline, Pfizer and a number of universities and university hospitals, to develop new COPD mapping tools. The project also involved patient advocacy groups such as the Lung Foundation

The authors contributed equally. We thank Martine Haas, Gerry George, and the three anonymous AMJ reviewers as well as Luca Berchicci, Raffaele Conti, Pedro de Faria, Lars Frederiksen, Nicolai Foss, Stine Grodal, Thorsten Grohsjean, Karin Hoisl, Ulrich Kaiser, H.C. Kongsted, Mark Lorenzen, Keld Laursen, Ram Mudambi, Maikel Pellens, Henning Piezunka, and Thomas Rønde for their very helpful comments and advice. Anders Ørding Olsen was funded by the Danish Council for Strategic Research's Programme Commission on Sustainable Energy and Environment.
Netherlands and the European Respiratory Society. "We were very surprised to learn from them that patients were so much concerned about the social consequences of COPD, like feeling isolated at home because they could only make it half way to the shops," a project scientist commented. "We had expected to hear mostly about symptoms, but effective treatments-from the patients' point of view-also ease the social constraints."

Curing widespread diseases like COPD (chronic obstructive pulmonary disease) poses a grand challenge to societies (Varmus, Klausner, Zerhouni, Acharya, Daar, \& Singer, 2003; Collins et al., 2011), alongside climate change (Howard-Grenville, Buckle, Hoskins, \& George, 2014), hunger, and water shortages (Godfray, Pretty, Thomas, Warham, \& Beddington, 2011), or privacy in the digital age (George, Haas, and Pentland, 2014; Dodgson, Gann, Wladawsky-Berger, Sultan, \& George, 2015). Grand challenges represent the most significant, complex, and interdependent problems that modern, and globally connected societies, face (Liu, et al., 2015). Governments and private foundations, such as the Bill

\footnotetext{
${ }^{1}$ This vignette, developed by the authors, is based on Innovative Medicines Initiative (2009) and interview material.
} 
\& Melinda Gates Foundation, provide substantial financial resources to the organizations and projects they deem most promising in finding solutions to grand challenges. Examples include the 21st Century Grand Challenges formulated by the U.S. Office of Science and Technology or the societal challenges in the "Horizon 2020" research funding program of the European Union.

Given the size and complexity of grand challenges, many organizations form partnerships to search jointly for solutions in what we will call search consortia. Intuitively, we would expect the institutional composition of search consortia to be salient for their success. Some partners may be particularly important for finding better solutions and convincing evaluating bodies from governments or foundations that the proposed solution of a consortium is superior to others and therefore deserves funding. Prior research suggests that the composition of search consortia reflects a division of labor between "differentiated" organizations (Lawrence and Lorsch, 1967), typically specialized in certain technological domains (e.g., Knudsen and Srikanth, 2014). However, as the introductory vignette illustrates, search consortia involve organizations without much technological capacity. Instead, it seems that patient advocacy groups were uniquely positioned to cover a facet of the problem that would otherwise have been disregarded by the consortium.

Advocacy groups are commonly referred to as secondary stakeholders within stakeholder theory (Clarkson, 1995), which defines the stakeholder in an organization as "any group or individual who can affect or is affected by the achievement of the organization's objectives" (Freeman, 1984: 46). ${ }^{2}$ Stakeholder theory would lead us to believe that the success of any solution proposed by a search consortium is related to the perceptions and acceptance of important stakeholders, for example, local communities, health care professionals, infrastructure providers, or society as a whole. Dissatisfied stakeholders can withhold resources (Frooman, 1999), organize disruptive protests (Clarkson, 1995), or trigger political intervention (Harrison and St. John, 1996). Stakeholder considerations are central to many grand challenge problems. Grand Challenges Canada, a government-funded foundation on issues

\footnotetext{
${ }^{2}$ Other examples of advocacy groups include Greenpeace, the Rainforest Alliance, or Transparency International. They are sometimes also referred to as NGOs or Civil Society Organizations.
}

of global health, is a case in point in that it stresses the need to consider the broader impact of solutions: "We focus on bringing successful innovation to scale, catalyzing sustainability and impact" (Grand Challenges Canada, 2016). The foundation projects that it will have saved 3 million lives and improved 35 million lives by 2030 through the projects funded.

However, prior literature has been relatively silent regarding the role of organizations in search consortia that are unlikely to contribute solutions at a sufficient operational and technical level. More generally, it seems we have too little knowledge about the heterogeneity of organizations in joint search that would enable us to explain the involvement of advocacy groups as representatives of grand challenge stakeholders. Our two research questions address this unresolved issue by asking why search consortia include advocacy groups and how advocacy groups help search consortia to obtain funding for implementing their proposal to solve a grand challenge problem.

Our theoretical reasoning rests on integrating stakeholder theory with a model of coordinated exploration in organizational search (Knudsen and Srikanth, 2014). Within the model, multiple organizations coordinate their individual search efforts through search consortia that reflect the complexity of the task environment of a given grand challenge. These consortia differ in their institutional composition and their proposals for how to solve a grand challenge. Governments or foundations evaluate the various proposals and allocate resources to search consortia to implement the most promising ones. Knudsen and Levinthal (2007) stress that the evaluation of alternative proposals occurs under uncertainty: evaluators compare alternatives based on minimum requirements and aspirations but it is uncertain whether an optimal solution exists or what it would look like.

The integration of stakeholder theory into this model allows us to identify two mechanisms through which advocacy groups benefit search consortia. First, stakeholder theory outlines how advocacy groups provide problem understanding and social acceptance assessments for innovation outcomes (Harrison and St. John, 1996; Heugens, van den Bosch, and van Riel, 2002; Harting, Harmeling, and Venkataraman, 2006). They can help identify areas of a search space that contain alternatives acceptable to stakeholders, in the sense that they will not face resistance, protests, or political intervention (Harrison and St. John, 1996). Second, advocacy groups can 
constrain or legitimize the actions of organizations (Jones, 1995; Frooman, 1999). Advocacy groups possess legitimacy, which originates from socially accepted and expected behavior (Suchman, 1995; Mitchell, Agle, and Wood, 1997). Legitimacy can "rub off" on a search consortium (Baum and Oliver, 1991; Bitektine, 2011) and serve as a signal to government or foundation evaluators that a proposed solution reflects the interests of relevant stakeholders and that these interests will be preserved once resources have been allocated.

Search and legitimacy mechanisms are likely to overlap. Therefore, we follow a contingency approach and investigate conditions under which one mechanism is likely to dominate. We suggest that the first mechanism, i.e., improved search, is more important when search consortia have increasingly dispersed technological knowledge and that the second mechanism, i.e., legitimacy, dominates when search consortia are inexperienced.

We test and support our theoretical predictions in a grant application context in which search consortia propose solutions and receive funding depending on their evaluation. Specifically, our research is based on unique data on 35,249 search consortia applying for funding to solve 2,349 grand challenge problems defined in the European Commission's Seventh Framework Program for Research and Technological Development (FP7). FP7 ran from 2007 to 2013 with a total budget of more than 50 billion Euros. In addition, our reasoning and measurements are informed by a series of semi-structured interviews with firm, advocacy group, and European Commission representatives involved in FP7. These conversations helped us gain a better understanding of the processes that led to the inclusion of advocacy groups and their benefits in search consortia.

Our research makes three novel contributions. First, we extend prior theory on organizational search by integrating it with stakeholder theory (Freeman, 1984; Freeman, Harrison, Wicks, Parmar, \& De Colle, 2010). Existing literature on joint search largely assumes that all organizations in a consortium search for solutions within their particular domain (Knudsen and Srikanth, 2014; Puranam and Swamy, 2016). We argue that the model is incomplete to the degree that it does not consider the importance of stakeholder acceptance of or support for any proposed solution. We show that advocacy groups can improve the search for solutions by assessing social acceptance (Harrison and St. John, 1996; Heugens et al., 2002; Harting et al., 2006) or giving legitimacy to the proposed solution vis-à-vis governments or foundations (Jones, 1995; Frooman, 1999). Existing studies largely disregard the fact that the value of any solution depends on its implementation.

Second, stakeholder theory has paid close attention to the conditions under which advocacy groups change the behavior of organizations (Frooman, 1999; Eesley and Lenox, 2006). However, research on innovative outcomes from advocacy group interaction with other organizations is scarce (exceptions include Harting et al., 2006). We provide a novel way of theorizing about the relationship between advocacy groups and innovative organizations which is not centered around avoiding protests, resistance, or political intervention (Harrison and St. John, 1996). Instead, we model advocacy groups as partners in shaping the search for solutions to grand challenges. Following our contingency approach, the benefits of involvement are particularly high for search consortia with widely dispersed technological knowledge and those that are inexperienced.

Third, our theoretical reasoning explicitly takes into account that grand challenges are heterogeneous in the degree to which their task environments require the acceptance or support of stakeholders. Hence, we provide conditions under which advocacy groups are systematically more likely to be included in search consortia. In other words, we go beyond existing models of coordinated exploration in which the institutional composition of organizations is assumed to be exogenously given (Knudsen and Srikanth, 2014; Puranam and Swamy, 2016).

In the following, we will first explain when a grand challenge task environment increases the likelihood that search consortia will include advocacy groups before we elaborate on the benefits of advocacy groups within a search consortium.

\section{THEORY AND HYPOTHESES}

\section{Including Advocacy Groups in Search Consortia}

The task environment of any grand challenge is typically complex in nature (Colquitt and George, 2011). In such an environment, many elements interact in uncertain and unpredictable ways (Simon, 1962; Anderson, 1999); for example, multiple potentially relevant technological solutions may target various aspects of a grand challenge with interconnected consequences. Organizations often collaborate with specialized organizations from different domains that attend to the complexity of a task environment (Knudsen and Srikanth, 2014). Prior research on 
coordinated exploration stresses the idea that the differentiation of organizations makes it possible to cope with a complex task environment (Lawrence and Lorsch, 1967). Differentiation characterizes an organization's local adaptation to tasks that are specific to that organization and to the environment. Highly complex task environments require both a high degree of differentiation to attend to the different facets of the task and a high degree of integration among the organizations to realize desirable outcomes (Knudsen and Srikanth, 2014). The nature of a grand challenge task environment is therefore an important predictor of the type of organizations that will form search consortia to address the particular challenge.

Grand challenge task environments can be heterogeneous along various dimensions. We focus on the degree to which the value of any solution depends on the acceptance or support of important stakeholders outside a search consortium. A policy officer from the European Commission describes the heterogeneity of grand challenge task environments like this:

Some aspects of highly specialized technologies, for example the specific ways of capturing the energy of ocean waves, require almost exclusively technological expertise. However, when these technologies are about to be implemented, it is important for us to learn beforehand what society thinks about it and to understand from where obstacles or resistance could emerge.

Stakeholders (a) have a legal, moral, or presumed claim on an organization or the ability to influence an organization to address a certain problem (Savage, Nix, Whitehead, and Blair, 1991; Frooman, 1999; Christmann, 2004) and (b) are in an existing or potential relationship with an organization (Mitchell et al., 1997; Bosse and Coughlan, 2016). Prior research stresses the notion of stakeholder saliency, defined as the likelihood that an organization will respond to stakeholder requests (Mitchell et al., 1997; Eesley and Lenox, 2006). Within our setting, stakeholders are directly affected by a grand challenge or the implementation of a solution. We argue that advocacy groups help search consortia address elements of the task environment which are related to stakeholder concerns and which add to its complexity.

Advocacy groups accumulate knowledge from stakeholders and other sources; they synthesize and aggregate it (Suchman, 1995). Patient advocacy groups, for example, not only support and educate people affected by a certain disease but also seek a deep understanding of the disease by collecting patient information on treatment and pharmaceutical effects (Terry, Terry, Rauen, Uitto, \& Bercovitch, 2007). As a consequence, advocacy groups build up repositories of specialized knowledge, which make them attractive partners for search consortia if the task environment requires the acceptance or support of stakeholders. Harrison and St. John (1996) show a number of examples of companies turning to advocacy groups for advice, such as oil companies' exploring practices which are unlikely to trigger protests or consumer goods producers seeking expertise on types of environmentally friendly packaging. The representative of an advocacy group confirms this:

We had the local expertise and were responsible for a work package that sought to integrate citizens into the project. That's why we were brought into the consortium.

Advocacy groups can provide or withhold access to knowledge (Eesley and Lenox, 2006). Accessing their accumulated knowledge can be much more efficient than interacting with individual stakeholders. In fact, organizations often manage relationships with stakeholder groups as a proxy, rather than with society as a whole (Clarkson, 1995). The head of research alliances at a large information and communications technology (ICT) firm underlined this motivation for including advocacy groups in a search consortium:

Advocacy groups cannot contribute much to the actual technology development. But by having them on board, we had access to the accumulated knowledge in the entire sector. Without them, our consortium would not have had 30 but rather 60 partners.

Taken together, we suggest that the inclusion of advocacy groups in search consortia becomes more likely the more elements of the task environment are influenced by stakeholder acceptance or support. In such task environments, search consortia have strong incentives to include advocacy groups because doing so allows them to manage the complexity that stems from the interaction of stakeholder elements with other-for example, technologyrelated-elements. Conversely, search consortia in task environments in which complexity originates predominantly from technological domains are unlikely to include advocacy groups. Our first hypothesis thus reads:

Hypothesis 1: The likelihood of search consortia including advocacy groups increases with the extent to which grand challenge task environments include elements related to stakeholder acceptance or support. 


\section{The Benefits of Advocacy Groups in Search Consortia}

Once a consortium has been formed, its members engage in coordinated exploration to identify a possible solution with which the consortium competes for resource allocation. Evaluators for governments or foundations assess alternative solutions to a grand challenge problem under conditions of uncertainty. Possible solutions can rarely be evaluated on the basis of experience and feedback. Instead, evaluation relies on cognitive processes in which evaluators have forward-looking models about the future outcomes of various alternatives (Gavetti and Levinthal, 2000). Accordingly, evaluators compare solutions proposed by different search consortia, and it remains uncertain whether superior solutions exist or what they entail (Knudsen and Levinthal, 2007). A search consortium becomes more likely to receive funding for implementing its proposal if evaluators consider it as superior to other proposals. In the following, we discuss how the involvement of advocacy groups increases the likelihood of receiving funding. We identify two mechanisms from stakeholder theory: improvements in the search for solutions and legitimacy effects, and show how they can be integrated in a model of coordinated exploration.

Improving the search for solutions. The need for coordination is inherent in models of joint search because the choices of partners in a search consortium are interdependent (Knudsen and Srikanth, 2014; Puranam and Swamy, 2016). Because the consortium must adopt a joint approach for exploring the search space, organizations need to align their models of the search space to achieve coordination. Yet greater alignment limits search to areas that are known to be jointly attractive to all organizations, which, as a result, stifles exploration of potentially superior alternatives (Knudsen and Srikanth, 2014). Davis and Eisenhardt (2011), for example, find that sharing information in hightechnology alliances leads firms to quickly agree on the lowest common denominator approach.

We argue that advocacy groups can help identify areas of the search space that contain solutions acceptable to relevant stakeholders in the sense that responsibilities are fulfilled and approaches satisfy stakeholder needs or expectations (Clarkson, 1995). More generally, advocacy groups are likely to differ from other members of the consortium like scientists in their initial representation of how the interdependent choices among consortium members lead to optimal solutions (Puranam and Swamy,
2016). Advocacy groups can trigger a process of deliberate exploration in which they guide a search consortium to consider various areas of the search space (Knudsen and Srikanth, 2014). As the introductory vignette suggests, they bring a stakeholder perspective to the search space, which can slow down the process with which mental models align to allow for a fuller exploration of the search space (Lounamaa and March 1987). Nevertheless, advocacy groups can also have negative effects on the process of identifying a possible solution. Their stakeholder focused knowledge can increase the need for coordination because their specific focus makes it harder for the other members to predict optimal choices (Puranam, Raveendran, and Knudsen, 2012) or they may simply be a source of confusion (Knudsen and Srikanth, 2014). Particularly powerful advocacy groups can constrain the search space that a consortium explores. Powerful actors can lead to a narrow search (Siggelkow and Rivkin, 2005), which limits exploration in favor of stability (Rivkin and Siggelkow, 2003). Prior empirical evidence, however, suggests the benefits of advocacy group involvement outweigh the potential disadvantages. Heugens et al. (2002), for example, show that stakeholder groups can build mutually enforcing relationships with firms. They use the term symbiotic learning for the process in which resulting products and practices become more aligned with varying interests. More recently, Flammer and Kacperczyk (2016) find that stakeholder orientation improves innovation outcomes by encouraging experimentation. Similarly, the executive from the ICT firm points out that involving advocacy groups increases the likelihood of solutions being adopted because they address the "right" problem:

If we know what the requirements are, we can look for solutions that really fit. It is clear that those [solutions] will have much higher impact. [...] The advocacy group in our consortium wanted the project to really have impact. They were pretty persistent in getting us out of our comfort zone.

Providing legitimacy. Recent contributions to the search literature highlight the evaluation and selection problem of innovative ideas (Knudsen and Levinthal, 2007; Piezunka and Dahlander, 2015; Criscuolo, Dahlander, Grohsjean, \& Salter, 2016). Integrating stakeholder theory into our model of search, we suggest the involvement of advocacy groups to be a source of legitimacy, defined as "a generalized perception or assumption that the actions of an entity are desirable, proper, or appropriate 
within some socially constructed system of norms, values, beliefs, and definitions" (Suchman, 1995: 574). Organizational legitimacy has often been characterized as vital for performance and survival (e.g., Certo, 2003) because legitimacy implies social support that facilitates access to resources (Drees and Heugens, 2013). Search consortia benefit from involving advocacy groups since their legitimacy may "rub off" on them (Baum and Oliver, 1991; Bitektine, 2011). Legitimate search consortia are regarded as "rational," which inspires confidence in them (Deephouse, 1999). They are also viewed as understandable and reliable and, consequently, less likely to fail due to unanticipated risks (Drees and Heugens, 2013). Consortia involving advocacy groups can therefore socially construct organizational legitimacy (Mitchell et al., 1997). An innovation manager from a manufacturing firm comments on the role of legitimacy:

They [the advocacy group] had a network of relevant decision makers in politics which allowed us to have presentations with key individuals. Our own networks would not have reached so far or some decision makers would not have been willing to listen to a large corporation such as ours.

We argue that advocacy groups can signal the desirability and appropriateness of the solution proposed by a search consortium vis-à-vis an evaluating body to improve the chances of being selected. Signals are reliable or credible to the receiver of the signal to the extent that the signal corresponds to the sought-after, but unobservable quality, of the party sending the signal ("signal fit") and the honesty of the signaler (Connelly, Certo, Ireland, \& Reutzel, 2011). Consortia can improve the evaluation of their proposed solution if they can send a strong signal that their exploration of the search space considers broader societal interests (Harrison, Bosse, and Phillips, 2010). Consortia that do not sufficiently consider broader stakeholder or societal interests in their exploration of the search space, i.e., "illegitimate" consortia, would not be able to involve advocacy groups because such groups would risk damage to their reputation. Put differently, advocacy group involvement is difficult and costly to imitate by illegitimate consortia. A policy officer involved with a grand challenge program of the European Commission tells us:

Reflecting civil society in a consortium is generally an advantage. However, when considerations, such as for citizen involvement or gender, are simply quick addons, this advantage will not materialize. Our expert evaluators are trained for this. They will not rubberstamp such things.

In addition, the involvement of advocacy groups ensures that these considerations do not fade away once resources have been allocated. The policy officer comments:

It's just difficult to assess the end use. The involvement of an NGO makes sure that an issue will be addressed.

In sum, we discuss two mechanisms by which the involvement of advocacy groups affects the evaluation of the proposed solution of a search consortium and hence its likelihood of receiving funding to implement the proposal. Theoretical considerations and empirical evidence suggest that advocacy groups improve the search for solutions. However, there are also concerns that advocacy groups can be a source of confusion or stagnation in the exploration of the search space. The legitimacy mechanism is more straightforward in predicting a positive effect from the involvement of advocacy groups. We suspect that search and legitimacy effects are likely to overlap in most search consortia and that the combined effect is more likely to be positive. Our second hypothesis therefore reads:

Hypothesis 2: There is a positive relationship between the involvement of advocacy groups in a search consortium and the likelihood of receiving funding.

\section{Contingency Effects for Advocacy Group Involvement in Search Consortia}

Hypothesis 2 rests on two interconnected and overlapping mechanisms for the benefits from advocacy group involvement in search consortia: (a) the capacity to identify a search space with acceptable solutions to stakeholders and (b) the signaling of legitimacy to evaluators. Both effects cannot be readily disentangled. To test their presence, we explore two contingencies in which (everything else held equal) one effect can be expected to be stronger than the other, i.e. a high dispersion of technological knowledge and a consortium's lack of experience, and vice versa (Olsen, Sofka, and Grimpe, 2016).

High technological dispersion in a search consortium describes a situation in which the members possess little overlapping technological expertise. There is, in other words, a high degree of differentiation because the organizations involved are specialized in different technological domains. 
Technological dispersion allows consortia to benefit from specialization advantages because they can better address a complex task environment (Lawrence and Lorsch, 1967). However, the search efforts of one organization may confound the feedback to another organization's efforts, and organizations cannot learn from feedback to adjust their models of the search space (Knudsen and Srikanth, 2014). Incorrect beliefs mutually confuse the organizations in a consortium, obscuring their ability to devise a joint approach to explore the search space. In that sense, high technological dispersion increases the ex-ante probability of experiencing mutual confusion. It implies that feedback to an organization's search efforts will be more seriously confounded by the search efforts of the other organizations in the consortium whose problem understanding and solving are based on individually comprehensible worlds (Boeker, 1989). Increasing technological dispersion therefore complicates learning from feedback and an adjustment of models of the search space, leading to a higher degree of mutual confusion (Knudsen and Srikanth, 2014).

We suggest that advocacy group involvement will be more beneficial in situations of high technological dispersion because advocacy groups can more effectively coordinate the individual efforts of the consortium members to explore the search space. Puranam and Swamy (2016) emphasize how important a representation or map of the interaction between individual choices in joint search can be for the success of a search consortium. They show that even incorrect representations of how the choices of organizations in a search consortium are interconnected are superior to the absence of representation because such absence limits learning from false negatives, i.e., misleading feedback, and foster learning from true negatives, i.e., useful feedback. Advocacy groups are uniquely positioned to provide such a map of the search space and resulting interconnections based on the knowledge that they have accumulated from stakeholders (Suchman, 1995). While their representation of interconnections may not be correct, it may be easier to accept for the other participants of a search consortium because advocacy groups are not tied to any particular technological domain. The innovation manager of a manufacturing firm explains:

Our consortium involved a diverse group of partners like OEMs [original equipment manufacturers], gas station chains, municipalities, universities, etc. The advocacy group could calm down internal exchanges and bring a sense of neutrality to discussions.
This notion is confirmed by the project manager of an advocacy group promoting innovation and technology in Germany:

Our unique feature was that we could provide a neutral platform for all partners involved in the consortium. That improved coordination immensely.

In that sense, the involvement of advocacy groups may improve the proposed solution because they decrease mutual confusion, particularly when mutual confusion is aggravated by high technological dispersion. We attribute this ability to the domain-spanning expertise of advocacy groups for a given problem. This reasoning is reflected in a comment by a manager from an electronics firm:

The advocacy group made sure that the slightly potty ideas did not get through and that people were respectful with each other. They [the advocacy group] facilitated convergence of the search strategy, leading to a consistent concept.

Our third hypothesis thus reads:

Hypothesis 3: There is a positive relationship between the involvement of advocacy groups in a search consortium and the likelihood of receiving funding, and this relationship is stronger the higher the technological dispersion within the search consortium.

Next, we focus on a setting in which the signaling effect of advocacy group involvement is particularly strong. We suggest that the positive effect of advocacy group involvement will be stronger if the focal consortium lacks experience. More precisely, we focus on a setting in which the search consortium does not have experience with coordinated exploration in a particular grand challenge task environment. In fact, liability of newness has been identified as an important origin of a lack of legitimacy (Hannan and Freeman, 1989). Evaluators may not yet have had an opportunity to learn about a consortium, and the consortium may not yet have demonstrated the reliability of its operations or the accountability of its resource use (Aldrich and Fiol, 1994; Choi and Shepherd, 2005).

In our context, consortia without experience in coordinated exploration for grand challenges are disadvantaged (Olsen et al., 2016). Advocacy groups cannot immediately offset the particular deficits from the lack of experience of a search consortium but they can create positive legitimacy signals in other areas. Hence, they reduce the uncertainty for 
evaluators about whether a consortium's exploration of the search space is desirable and appropriate. Since involving advocacy groups in a search consortium can signal legitimacy, inexperienced consortia can send a particularly strong signal of legitimacy when they succeed in involving advocacy groups. Stakeholders have been found to lend support to older organizations with characteristics related to experience such as reliability and accountability (Choi and Shepherd, 2005). Similarly, advocacy groups may be reluctant to enter into an inexperienced consortium as doing so could compromise their reputation. This reasoning is echoed by an expert evaluator of a grand challenge program:

Most advocacy groups I have seen involved in consortia and that I have talked to are really serious and professional. Of course, occasionally you see a small group with a lousy homepage located in the middle of nowhere. But that's typically not the case. They know that they cannot put their brand into the hands of whomever. It's not easy to get these guys involved.

Advocacy group involvement constitutes therefore an especially credible signal to evaluators that a consortium's exploration of the search space in fact reflects the interests of stakeholders. In other words, advocacy group involvement is particularly difficult and costly to imitate by inexperienced consortia. Our fourth hypothesis reads as follows:

Hypothesis 4: There is a positive relationship between the involvement of advocacy groups in a search consortium and the likelihood of receiving funding, and this relationship is stronger when the consortium lacks experience.

\section{DATA AND METHODS}

\section{Data}

To test our hypotheses, we develop a dataset based on all applications submitted to the FP7, the European Commission's Seventh Framework Program for Research and Technological Development. Framework Programs are institutionalized on the principle that the problems addressed by them have a magnitude of importance and difficulty that goes beyond the capacities of individual EU member states. We restrict our sample to the "Cooperation" part of the program that is dedicated to funding collaborative efforts to develop new solutions to problems and areas that address grand challenges. Our level of analysis is the consortium, which is described, along with its approach to exploring the search space, in the grant application submitted. The applications are reviewed by experts appointed by the European Commission who evaluate their likelihood to find a high-value solution. The applications relate to one of the following themes: food and agriculture, health, information and communication technologies, nano technologies, energy, environment, transportation, security, and socio-economic and humanitiesrelated issues. Within each of these areas, the European Commission announced in total 2,349 calls for proposals during the seven-year period from 2007 to 2013. Each call is embedded within 192 specific problem areas with a total funding allocation of over 50 billion Euros.

We observe a total of 35,249 consortia that submitted applications for funding. To fully understand the process leading up to the submission of the funding applications observed in our data, we interviewed two experts from the European Commission, three national expert advisors for grant applications, and eight experts from applying consortia, including firm managers and advocacy group representatives. The interviewees described how an individual organization or a group of organizations will initially identify a call which describes a problem of interest to the organization(s). The organization or the existing group will then identify potential collaborators with relevance to the development of a solution, and these will iteratively identify and approach additional collaborators to eventually form a consortium they believe will be competent in proposing a solution that will receive superior evaluations compared with other proposals and will therefore receive funding. Typically, these organizations will explore several approaches before they settle on what they believe to be the approach to exploring the search space with the highest likelihood of finding a high-value solution. The collaborators then explain their approach in detail and provide information on the role of the individual organizations and the knowledge as well as resources they will commit to the search consortium. This detailed description of the search approach is submitted to the European Commission, where expert evaluators assign a score ranging from 0 to 100, which captures the likelihood of finding a high-value solution vis-à-vis the original call. ${ }^{3}$ Each call has

\footnotetext{
${ }^{3}$ Because research outcomes remain uncertain, a score of 100 does not mean that a consortium is certain to find a high-value solution.
} 
a dedicated evaluation committee and budget allocation. Hence, there is no competition or comparison between consortia responding to different calls.

The empirical setting has multiple advantages. First, we theorize at the consortium level, which is reflected in the dataset. Organization- or inventionlevel (e.g., patent-level) information is likely to suffer from biases due to aggregation of information. Second, we theorize about heterogeneous search consortia. The dataset allows us to capture multiple search consortia within the same problem areas, which are exogenously defined by the European Commission for all consortia alike. Third, we investigate all search consortia that submitted to FP7. Hence, the potential for selection biases originating from capturing only successful applicants (i.e., those granted funding) is removed. Finally, the European Commission follows consistent procedures but defines heterogeneous problems in its call for proposals texts inviting project applications. Hence, we can observe a multitude of grand challenge problems and draw comparisons.

To test our hypotheses, we extend the grant application data in a number of ways. First, we use VAT numbers and organizations' names to identify the organizations of all search consortia in Bureau von Dijk's Orbis database. From this, we collect data on industry affiliation and patent portfolios of the organizations. Second, we extend our dataset with information from the 2,349 call texts published by the European Commission by means of a content analysis. Third, we use data from the Orbis database and the World Bank to construct an instrumental variable. We describe the variables in further detail below.

\section{Variables}

Dependent variables. The first dependent variable is advocacy group inclusion. - Hypothesis 1 predicts the inclusion of advocacy groups in a search consortium. We use North American Industry Classification System (NAICS) codes to identify advocacy groups in our data on the basis of the activities in which the organizations are engaged. Specifically, we define organizations as potential advocacy groups if they are registered in one of the groups that cover "Religious Organizations," "Foundations," "Voluntary Health Organizations," "Human Rights Organizations," "Environment, Conservation and Wildlife Organizations," "Civic and Social Organizations," and "Business, Professional, Labor, Political, and Similar Organizations." Subsequently, we manually check and code the organizations to remove false positives. We observe 1,284 consortia with at least one advocacy group included (3.64\% of the sample).

The second dependent variable is likelihood of receiving funding. Hypotheses 2, 3, and 4 predict the likelihood of a consortium to receive funding for implementing its proposed solution to a grand challenge problem. Within the FP7 setting, the likelihood of funding increases with the evaluation score assigned to each funding application by three to five independent experts for each call. These are hired by the European Commission on the basis of their expertise within the particular problem area, and they initially evaluate the applications individually before subsequently meeting in Brussels to determine the final scoring of the proposal outlined by the consortium. This meeting is moderated by a representative of the European Commission and an additional independent expert to ensure full consideration of the input of all experts. Evaluators assess both the consortium and its application, i.e., the evaluation is not double-blind. Our setting resembles the theoretical model of Knudsen and Levinthal (2007), in which evaluators compare alternative solutions to one another and choose the most promising one. Accordingly, our dependent variable is an ordinal measure, with the final score ranging from 0 to 100 and being assigned by experts on the basis of whether the application is likely to solve the underlying problem. Specifically, the experts assess the technological and scientific excellence of the proposal, the quality and efficiency of the implementation and management (including the competences of the participants and the quality of the consortium), and the impact of the solution regarding the exploitation and dissemination of the results and scientific outputs (European Commission, 2007).

Consistent with our theoretical setup, we use a measure of the likelihood of receiving funding for implementing a proposed solution rather than the outcome of the project. This has the advantage of isolating and analyzing the effect of advocacy groups without unobserved influences. Such influences from exogenous factors are likely to occur during the execution phase, creating contingencies and issues that affect the eventual outcome of search (Ring and van de Ven, 1994). They would reduce the ability to capture the influence of the variables of interest as this could be confounded by a range of alternative explanations. The ability to observe approved and rejected applications is an additional benefit of using ex-ante measures. Ex-post measures inherently 
suffer from selection bias since the rejected applications remain unobserved in the analysis.

Explanatory variables. The first explanatory variable is stakeholder elements of the task environment. In Hypothesis 1 we predict that the probability of advocacy groups being part of a search consortium increases if the task environment includes elements related to stakeholder acceptance or support. Within our empirical context, the problem description of FP7 call texts describes the task environment. We deduce elements related to stakeholder acceptance or support in a call text through a content analysis. We conduct initial interviews with experts from the framework programs of the European Commission to obtain an operational definition indicating how elements of stakeholder acceptance or support would be expressed in call texts. This operational definition emphasizes interaction, communication, and/or consultation with society as a whole or a variety of groups such as actors from civil society, users, or industries. Content analysis allows us to identify such task environments more systematically by relying on the principle that cognitive schemas can be inferred from the systematic, replicable analysis of text, given the importance of language in human cognition (for a recent review see Duriau, Reger, and Pfarrer, 2007).

The appendix shows two examples of call texts. Within our reasoning, the call text in Appendix 1 "Collective Awareness Platforms for Sustainability and Social Innovation (ICT-2013.5.5)" includes more elements related to stakeholder acceptance or support than the call text in Appendix 2 "Co-morbidity between infectious and non-communicable diseases (HEALTH.2012.2.3.2-2)." Our ultimate goal is to establish a coding dictionary of words and phrases that systematically indicate elements related to stakeholder acceptance or support in FP7 call texts. To the best of our knowledge, we are the first to apply content analysis to call texts. To develop a dictionary we go through a multi-layered, iterative process of dictionary creation, validation, and reliability testing following Vergne (2012) and Duriau et al. (2007). Appendix 3 provides details on the content analysis process and protocol.

We develop an initial dictionary of words or short phrases reflecting the operational definition and iteratively improve it through discussions with nine experienced grant readers and writers. As a result, we retain a list of 66 words, such as "civil society," "inclusive," "networking," "socioeconomic," or "transfer," indicating elements of stakeholder acceptance or support in a call text (see Appendix 4 for the entire dictionary). We use the software tool LIWC to count the occurrence of items from the dictionary in each of the 2,349 call texts and scale this count by the length of the text. ${ }^{4}$ Individual words from the dictionary could have multiple meanings or meanings could vary by context. We experiment therefore with narrower or broader dictionaries, which lead to very similar classifications of call texts (correlations range from 0.92 to 0.94 ).

Finally, we ask two experienced evaluators of EU grant proposals to read a sub-sample of 30 call texts and assess the degree to which those contain elements of stakeholder acceptance or support in the task environment of the calls. On the basis of these expert ratings, we calculate an intercoder reliability $\alpha$ of 0.81 (Krippendorff, 2004) with the fractional word count obtained using our dictionary, which can be considered high. Accordingly, we use the fractional word count in different calls to measure differences in the extent to which task environments include elements of stakeholder acceptance or support.

The second explanatory variable is advocacy group involvement. To test Hypothesis 2 on the relationship between the involvement of advocacy groups and the likelihood of receiving funding, we count the number of advocacy groups included in a consortium. We perform consistency checks using alternative measures for advocacy group involvement: (a) a dummy for the inclusion of advocacy groups, (b) the share of advocacy groups relative to the total number of consortium organizations, and (c) the amount of funding allocated to advocacy groups in the application submitted by a given consortium. Advocacy group involvement is then interacted with the following two variables to test Hypotheses 3 and 4.

The third explanatory variable is knowledge dispersion. We use a Herfindahl index to calculate the concentration of International Patent Classification (IPC) classes of the patents held by all consortium members at the European Patent Office (EPO). Patent classes reflect distinct technologies as defined by patent offices. They group similar technologies within classes and separate them from increasingly different technologies in other classes. Patent

\footnotetext{
${ }^{4}$ We limit the content analysis to the parts of the call texts describing the task environments with headings such as scope, problem definition, and expected or targeted outcomes. Administrative rules or general descriptions of FP7 are excluded.
} 
classes have been frequently used in the literature to reflect such similarities (Jaffe, 1986). Within the IPC, patented technologies can appear in 129 different technology classes at the three-digit level. To facilitate interpretation, we use the inverse Herfindahl index of IPC classes as a measure of dispersion, with a value of 0 representing full concentration and a value of 1 representing full dispersion.

The forth explanatory variable is lack of experience. Because search consortia, particularly those that involve a multitude of organizations, may not engage in coordinated exploration several times without changing the exact composition of the consortium, we suggest that consortia particularly lack experience when the leader is inexperienced. The consortium leader plays an important role as it will ultimately submit the grant application to the European Commission. As a consequence, the leader is particularly prominent and visible to the evaluating body. We create a dummy variable for whether the organization leading a search consortium was participating in an FP7 application for the first time. We experiment with alternative measures, such as below-median participation experience, first-time participation in FP7 or its predecessor FP6 (Sixth Framework Program, 2002-2006), and with the share of all organizations in a consortium that participated in FP7 for the first time.

Control variables. Several other variables have been found to influence the likelihood of receiving funding in FP7 (Olsen et al., 2016). Accordingly, we include a number of control variables at the consortium level. Since universities are particularly important in the early stages of an innovation process (Kotha, George, and Srikanth, 2013), we include number of universities in the search consortium. Moreover, we include a count measure of the number of different partner types involved in the consortium, such as firms, universities, etc. We also control for total number of participants in the consortium because a higher number of participants increases the opportunities for specialization within a consortium. Further, a larger application in terms of funding sought may influence the evaluation, which is why we include total project costs in millions of Euros.

To capture the consortium's absorptive capacity (Cohen and Levinthal, 1990), we include total patent stock of all participants in a consortium. Patents may also signal a certain level of technological competence and expertise to the evaluating body. We depreciate the patent stock at a rate of $15 \%$ per year annually between the time of patenting and the application to FP7 to account for the depreciation of knowledge over time. Furthermore, experience with coordinated exploration is likely to influence the approach to exploring the search space (Love, Roper, and Vahter, 2014). Accordingly, we include participants' total experience measured as the number of prior participations in search consortia, either in FP6 or FP7. By going back to FP6, we can observe experience for the period from 2002 to 2013 . However, FP6 data are restricted to approved and funded applications, which may underestimate the learning effects in our data. As an alternative, we use FP7 data only. Finally, we include a count variable for number of different regions of the involved participants (Eastern, Western, Northern and Southern Europe, Africa, Asia, North America and Australia, and South America) to capture the geographical breadth of the consortium.

\section{Model}

Our theoretical model has two interconnected stages. Hypothesis 1 predicts the likelihood of enrolling advocacy groups in a search consortium, while the remaining hypotheses predict a consortium's likelihood of receiving funding as a result of advocacy group involvement. The decision to include advocacy groups in a consortium is likely to be non-random with several selection and selfselection processes at work. Factors associated with such selections could influence the likelihood of receiving funding, i.e., there is the potential for biased estimation results (Certo, Busenbark, Woo, \& Semadeni, forthcoming). Hence, we estimate a twostage system of equations in which we make several efforts to control for endogeneity.

First stage selection. We initially predict the likelihood that an advocacy group will be included in a consortium using a probit model with robust standard errors. We include the variable measuring stakeholder elements of the task environment to test Hypothesis 1, all independent variables and dummies for the problem-area fixed effects from the second stage, and an instrumental variable. We then calculate the inverse Mills ratio from this result and include it as a control in the second stage (Hamilton and Nickerson, 2003; Bascle, 2008).

In our context, a suitable instrumental variable must be correlated with the inclusion of advocacy groups in a search consortium, conditional on the other covariates. Moreover, it must not be correlated with the error term in the equation explaining the likelihood of receiving funding, conditional on the other covariates. We suggest that the "supply" of 
advocacy groups in a country relative to the size of the country satisfies these conditions. Using the Orbis database, we calculate the total number of advocacy groups according to the definition presented above that were active in a country as of 2013. We divide this number by the country's GDP in millions of USD (data taken from the World Bank statistics portal). ${ }^{5}$ We then merge this variable by the country of the organization leading the consortium. The instrument rests on the assumption that consortium leaders in countries with a high supply of advocacy groups are more likely to include an advocacy group in a consortium because there are more opportunities in close geographical proximity. At the same time, this variable should be unrelated to a consortium's likelihood of receiving funding. The evaluation process does not favor organizations from particular countries as long as they are eligible to apply. Once a consortium has decided to include an advocacy group (or not), it is irrelevant for the evaluation how many other advocacy groups exist in any particular country. The final step of the evaluation takes place in Brussels under the supervision of the European Commission. Individual evaluators are not allowed to favor particular countries in their evaluations. Such measures of supply have frequently been used as instruments in economic analyses (e.g., Hummels, Jørgensen, Munch, \& Xiang, 2014).

Second stage OLS. We use a fixed-effects ordinary least squares (OLS) model with robust standard errors to estimate the relationship between advocacy group involvement and the likelihood of receiving funding (Hypothesis 2). Our data cover 192 problem areas nested within the broader themes described above. It is plausible that advocacy groups are of different importance in certain problem areas. To account for the data structure and to ensure that consortia with different levels of advocacy group involvement are compared to applications directed at similar problems, we estimate our models with fixed-effects at the level of the 192 problem areas. This holds the potential influence from unobserved heterogeneity between these fixed areas which may otherwise increase or decrease the estimated contribution of advocacy groups. Hence, we analyze how advocacy groups influence the likelihood of receiving funding by testing our hypotheses within different problem areas. To test Hypotheses 3 and 4, we include multiplicative interaction terms between advocacy group involvement and knowledge dispersion and a lack of experience,

\footnotetext{
${ }^{5}$ Alternatively, we use the absolute number of advocacy groups in a country and the number of advocacy groups as a share of the "world supply" of advocacy groups.
}

respectively. The hypotheses would be supported if the interaction effects are positive and significant.

Consistency checks. We conduct a number of consistency checks to ensure the robustness of our analysis. First, we test the sensitivity of the results when we use alternative measurements of the main explanatory variables as described above. Second, we restrict our sample to search consortia, which include at least one firm participant, given that some calls may be targeted at problems without business relevance. Third, we attempt to address potential endogeneity concerns in two additional ways. Since the success of a consortium may be driven by unobserved characteristics that also influence the likelihood of attracting advocacy groups, we include the past evaluation score of a consortium leader's applications as an additional explanatory variable in the first and second stage estimations. Past performance is likely to account for many unobserved quality characteristics which could potentially be a source of endogeneity. This measure of past performance is calculated using all previous applications involving the consortium leader in the sample, whether as leader or participant.

Finally, we test the stability of the results from our selection models by contrasting them with a nonparametric approach of creating a matched sample and repeating all regressions for the matched sample. The matching goal is to improve the balance between consortia, including advocacy groups (treated consortia) and the control group, based on pretreatment factors which may potentially have confounding effects (Iacus, King, and Porro, 2011). Within our setting, the past performance evaluation score of the consortium leader is particularly suitable for capturing many pretreatment factors. This approach rests on the assumption that better consortia (measured by past performance) have higher chances to obtain funding and at the same time to include advocacy groups. In that sense, the identifying assumption is that the treatment is random given the matching on past performance. We create the matched sample by applying coarsened exact matching techniques (Azoulay, Graff Zivin, and Wang, 2010; Iacus et al., 2011). Matching occurs by dividing the data into 1,742 strata which are the result of the 192 call problem areas and a division (coarsening) of the past performance evaluation scores into 10 equally sized groups. ${ }^{6}$ Each observation is assigned to

\footnotetext{
${ }^{6}$ Coarsened exact matching relies on the choice of a finite number of strata from the joint distribution of covariates instead of attempting precise matches. Given that evaluation scores range between 0 and 100, 10 groups appear appropriate. Results are not sensitive to the choice.
} 
a stratum. We create the matched sample by discarding all observations for which no treated and control consortia exist in the same stratum either because no consortia including advocacy groups applied in a problem area or there were no control consortia with past performance evaluation scores in the same groups. In these cases, selection may have occurred. We discard 8,987 observations based on these criteria and retain a matched sample of 27,501 observations for which we repeat the regressions from the main models without a selection equation.

\section{RESULTS}

Table 1 reports summary statistics and Table 2 shows pairwise correlations and the variance inflation factor (VIF) for the variables used in our model. The individual VIFs are all below 2.8 and the mean VIF is 1.38 , which does not raise any concerns of multicollinearity (Belsley, Kuh, and Welsh, 1980). The descriptive statistics show that the average score assigned by evaluators to a consortium's application is 37 , which is comparatively low, indicating a competitive evaluation procedure. ${ }^{7}$ Moreover, the average advocacy group involvement in a consortium is 0.04 with a maximum of four advocacy groups involved. One third of all consortia lack experience in the sense that the leading organization did not previously participate in FP7. The average consortium has an intermediate degree of knowledge dispersion, as evidenced by the moderate value of the Herfindahl index (0.33). The variable generated through content analysis shows that about $3 \%$ of the words in an average call relate to stakeholder elements of the task environment. On average, consortia include slightly more than four university participants and almost two different types of organizations (typically firms and universities). Further, the average consortium has almost 10 participants from three different geographical regions and project costs of about 5 million Euros. Finally, the average experience of participants with other applications in FP7 is low, as is on average the participants' patent stock.

Table 3 presents the results of our regression analyses. Model 1 shows the results of our first-stage probit model. The coefficient of the instrumental variable shows a highly statistically significant relationship, indicating a strong instrument. As predicted, the degree to which a call text includes

\footnotetext{
${ }^{7}$ The score required to obtain funding varies from call to call. It is typically greater than 70 .
}

elements of stakeholder acceptance or support shows a significant and positive coefficient, providing support for Hypothesis 1. By formulating the call in a specific way, evaluators can apparently influence the institutional composition of a search consortium. In addition to testing Hypothesis 1, the first-stage probit allows us to calculate the inverse Mills ratio to correct for endogeneity in the OLS regression models 2 to 5 . Model 2 regresses the evaluation score on our set of control variables and the main explanatory variable, the number of advocacy groups involved in a search consortium. The variable shows a positive and significant coefficient, providing support for Hypothesis 2. Involving advocacy groups in search consortia is in fact positively associated with the likelihood of receiving funding for implementing a proposed solution.

Further, Table 3 shows the results for our interaction Hypotheses 3 and 4 in models 3 to 5. Model 3 includes our measure of knowledge dispersion and the multiplicative interaction term between knowledge dispersion and the number of advocacy groups. We find higher knowledge dispersion of the consortium partners to be negatively related to the likelihood of receiving funding. Specifically, we had argued that higher dispersion implies a higher ex-ante risk of mutual confusion and, as a result, increasing difficulties to coordinate between the partners in joint search (Knudsen and Srikanth, 2014). Model 3 shows that advocacy group involvement can effectively mitigate the negative coefficient of increasing knowledge dispersion: the interaction effect is positive and significant, providing support for Hypothesis 3. In other words, advocacy group involvement pays off the most when the ex-ante likelihood of successful coordination between the partners is low due to a high dispersion of knowledge.

Model 4 includes our measure for the lack of prior experience of the consortium leader, and the multiplicative interaction with the number of advocacy groups. As expected, we find the variable to be negatively associated with the likelihood of receiving funding. A consortium leader lacking experience increases the uncertainty that evaluators from governments or foundations associate with the consortium. Advocacy group involvement, however, again mitigates the negative coefficient, as evidenced by the positive and significant interaction effect. We attribute this finding to the legitimacy of advocacy groups: if consortia with an inexperienced leader succeed in involving advocacy groups, they are able to send a particularly strong signal about the 
TABLE 1

Summary statistics

\begin{tabular}{|c|c|c|c|c|}
\hline Variables & Mean & S.D. & Min & $\operatorname{Max}$ \\
\hline Likelihood of receiving funding (evaluation score) & 37.12 & 32.55 & 0 & 100 \\
\hline Number of advocacy groups & 0.04 & 0.22 & 0 & 4 \\
\hline Knowledge dispersion & 0.33 & 0.28 & 0 & 1 \\
\hline Stakeholder elements of the task environment & 2.96 & 1.06 & 0.42 & 8.99 \\
\hline Number of universities & 4.33 & 3.21 & 0 & 70 \\
\hline Project cost (million EUR) & 5.28 & 10.32 & 0 & 947.32 \\
\hline Participants' total patent stock & 0.08 & 0.34 & 0 & 5.81 \\
\hline Participants' total experience & 0.12 & 0.17 & 0 & 4.27 \\
\hline Geographical breadth & 3.03 & 1.06 & 1 & 9 \\
\hline
\end{tabular}

consortium's legitimacy to the evaluator. Hypothesis 4 hence receives support.

Since we estimate OLS regression models, the coefficient estimates can be interpreted as marginal effects. We find that one additional advocacy group in a consortium increases the evaluation by almost one point. Considering the mean evaluation score of 37 , this equals an increase of almost 3 percentage points. In comparison, adding one university to the consortium increases the evaluation score by only half a point. The difference in coefficients is statistically significant at the $1 \%$ level. The importance of advocacy groups becomes even more visible when looking at the interaction effects. Advocacy groups can more than offset the negative effect of high knowledge dispersion and significantly reduce the negative effect of a lack of experience. As the descriptive statistics indicate, both the dispersion of technological knowledge and a lack of experience are attributes that characterize many of the consortia in our sample.

The results for the control variables are fully consistent across models 2 to 5. Involving universities increases the likelihood of receiving funding as expected. Apparently, universities improve a consortium's ability to explore the search space (e.g., Kotha et al., 2013). Moreover, more different types of partners in the consortium, a higher number of participants, and a higher patent stock improve, as expected, the likelihood of receiving funding. However, consortia with highly experienced partners in FP6 and FP7 do not benefit. This may be due to the fact that those consortia have a higher tendency to choose the lowest common denominator when devising a joint search strategy. They may be less inclined to accept critical viewpoints, and their search may become dominated by routines, leading to an overall lower degree of exploration of the search space. Moreover, we find that geographical breadth harms the likelihood of receiving funding, indicating that pronounced regional differences between the partners may impede coordination. Finally, the project costs are not significantly related to the likelihood of receiving funding.

As described above, we perform several consistency and sensitivity checks which we present in an appendix available from the authors upon request. We investigate alternative measurements of our main explanatory variable (Tables A1 to A3), alternative measurements of the lack of experience theorized in Hypothesis 4 (Tables A4 to A6), a subsample that includes only consortia with at least one firm participant (Table A7), and a set of regressions that control for the consortium leader's past performance (Table A8). Finally, we repeat the regressions from the main model for a matched sample instead of relying on a selection equation. The matched sample originates from requiring that both consortia, including advocacy groups (treated consortia), and the control group have been applied in the same problem areas and have similar past performance evaluation scores (coarsened into 10 groups). This condition holds for 27,501 consortia. Table A10 shows the results for the regression results for this reduced sample. All results turn out to be fully consistent.

\section{DISCUSSION}

Advocacy groups are unusual partners in the context of organizational search. They typically do not have the technological capacity and skills to engage in search at a sufficient operational and technical level. Yet, we frequently observe advocacy groups participating in consortia of organizations that 
TABLE 2

Pairwise correlations

\begin{tabular}{|c|c|c|c|c|c|c|c|c|c|c|c|}
\hline Variables & (1) & (2) & (3) & (4) & (5) & (6) & (7) & (8) & (9) & (10) & (11) \\
\hline $\begin{array}{l}\text { (1) Likelihood of receiving } \\
\text { funding (evaluation score) }\end{array}$ & 1.00 & & & & & & & & & & \\
\hline (3) Lack of experience & $\begin{array}{c}-0.05 \\
(0.00)\end{array}$ & $\begin{array}{r}-0.03 \\
(0.00)\end{array}$ & 1.00 & & & & & & & & \\
\hline \multirow[t]{2}{*}{$\begin{array}{l}\text { (5) Stakeholder elements of the } \\
\text { task env. }\end{array}$} & -0.03 & 0.05 & -0.02 & & 1.00 & & & & & & \\
\hline & $(0.00)$ & $(0.00)$ & $(0.00)$ & $(0.00)$ & & & & & & & \\
\hline (6) Number of universities & $\begin{array}{c}0.20 \\
(0.00)\end{array}$ & $\begin{array}{c}0.06 \\
(0.00)\end{array}$ & $\begin{array}{c}0.01 \\
(0.03)\end{array}$ & $\begin{array}{c}0.12 \\
(0.00)\end{array}$ & $\begin{array}{c}0.06 \\
(0.00)\end{array}$ & 1.00 & & & & & \\
\hline (7) Number of partner types & $\begin{array}{c}0.18 \\
(0.00)\end{array}$ & $\begin{array}{c}0.05 \\
(0.00)\end{array}$ & $\begin{array}{c}-0.07 \\
(0.00)\end{array}$ & $\begin{array}{c}0.07 \\
(0.00)\end{array}$ & $\begin{array}{c}-0.15 \\
(0.00)\end{array}$ & $\begin{array}{c}-0.08 \\
(0.00)\end{array}$ & 1.00 & & & & \\
\hline (10) Participants' total patent stock & $\begin{array}{c}-0.01 \\
(0.01)\end{array}$ & $\begin{array}{c}0.00 \\
(0.80)\end{array}$ & $\begin{array}{c}-0.03 \\
(0.00)\end{array}$ & $\begin{array}{c}-0.11 \\
(0.00)\end{array}$ & $\begin{array}{c}-0.02 \\
(0.00)\end{array}$ & $\begin{array}{c}0.02 \\
(0.00)\end{array}$ & $\begin{array}{c}0.16 \\
(0.00)\end{array}$ & $\begin{array}{c}0.18 \\
(0.00)\end{array}$ & $\begin{array}{c}0.12 \\
(0.00)\end{array}$ & 1.00 & \\
\hline (11) Participants' total experience & $\begin{array}{c}0.05 \\
(0.00)\end{array}$ & $\begin{array}{c}0.05 \\
(0.00)\end{array}$ & $\begin{array}{c}-0.39 \\
(0.00)\end{array}$ & $\begin{array}{c}0.05 \\
(0.00)\end{array}$ & $\begin{array}{c}-0.00 \\
(0.80)\end{array}$ & $\begin{array}{c}0.26 \\
(0.00)\end{array}$ & $\begin{array}{c}0.10 \\
(0.00)\end{array}$ & $\begin{array}{c}0.32 \\
(0.00)\end{array}$ & $\begin{array}{c}0.12 \\
(0.00)\end{array}$ & $\begin{array}{c}0.13 \\
(0.00)\end{array}$ & 1.00 \\
\hline (12) Geographical breadth & $\begin{array}{c}0.19 \\
(0.00)\end{array}$ & $\begin{array}{c}0.08 \\
(0.00)\end{array}$ & $\begin{array}{c}0.02 \\
(0.00)\end{array}$ & $\begin{array}{c}0.05 \\
(0.00)\end{array}$ & $\begin{array}{c}0.05 \\
(0.00)\end{array}$ & $\begin{array}{c}0.46 \\
(0.00)\end{array}$ & $\begin{array}{c}0.08 \\
(0.00)\end{array}$ & $\begin{array}{c}0.48 \\
(0.00)\end{array}$ & $\begin{array}{c}0.09 \\
(0.00)\end{array}$ & $\begin{array}{c}0.01 \\
(0.09)\end{array}$ & $\begin{array}{c}0.09 \\
(0.00)\end{array}$ \\
\hline Mean Variance Inflation Factor & 1.38 & & & & & & & & & & \\
\hline
\end{tabular}

Notes: Level of significance in parentheses. ${ }^{* * *} \mathrm{p}<0.01,{ }^{* *} \mathrm{p}<0.05,{ }^{*} \mathrm{p}<0.1$.

seek solutions to grand challenge problems. Prior research on coordinated exploration has been relatively silent regarding the heterogeneity of organizations in joint search. Hence, our research is guided by two questions: Why do search consortia include advocacy groups, and how do these groups help search consortia to obtain funding in order to implement a proposed solution? We test our model of coordinated exploration by using all grant applications submitted to the FP7, a major European research funding program dedicated to addressing grand challenge problems. Our grant application context complements other recent research on the evaluation and selection of innovative ideas but focuses on the composition of search consortia (e.g., Piezunka and Dahlander, 2015; Boudreau, Guinan, Lakhani, \& Riedl, 2016; Criscuolo et al., 2016).

Existing literature has frequently characterized grand challenges as the most significant, complex, and interdependent problems that modern and globally connected societies are facing (e.g., Omenn, 2006; Colquitt and George, 2011; Liu et al., 2015). Governments or foundations allocate substantial resources to motivate organizational search for solutions. However, these institutions favor solutions to grand challenges which go beyond technological excellence and novelty. Our research finds that grand challenge task environments differ in the extent to which they include stakeholder elements. In the absence of stakeholder acceptance, the effects from technologically excellent solutions may be disappointing because stakeholders may not implement solutions or resist them. Greater focus on stakeholder concerns increases the complexity that search consortia need to manage and, as a consequence, the likelihood of search consortia including advocacy groups (Mitchell et al., 1997). Advocacy groups, in that sense, attend to a certain facet of the task environment. All members of a consortium benefit from this particular division of labor (Lawrence and Lorsch, 1967).

Once advocacy groups are involved, a search consortium engages in coordinated exploration (Knudsen and Srikanth, 2014). We identify two overlapping mechanisms related to search and legitimacy that we find improve the evaluation of the proposed solution. First, since advocacy groups 
TABLE 3

Main model results predicting the inclusion of advocacy groups (selection) and the likelihood of receiving funding (OLS)

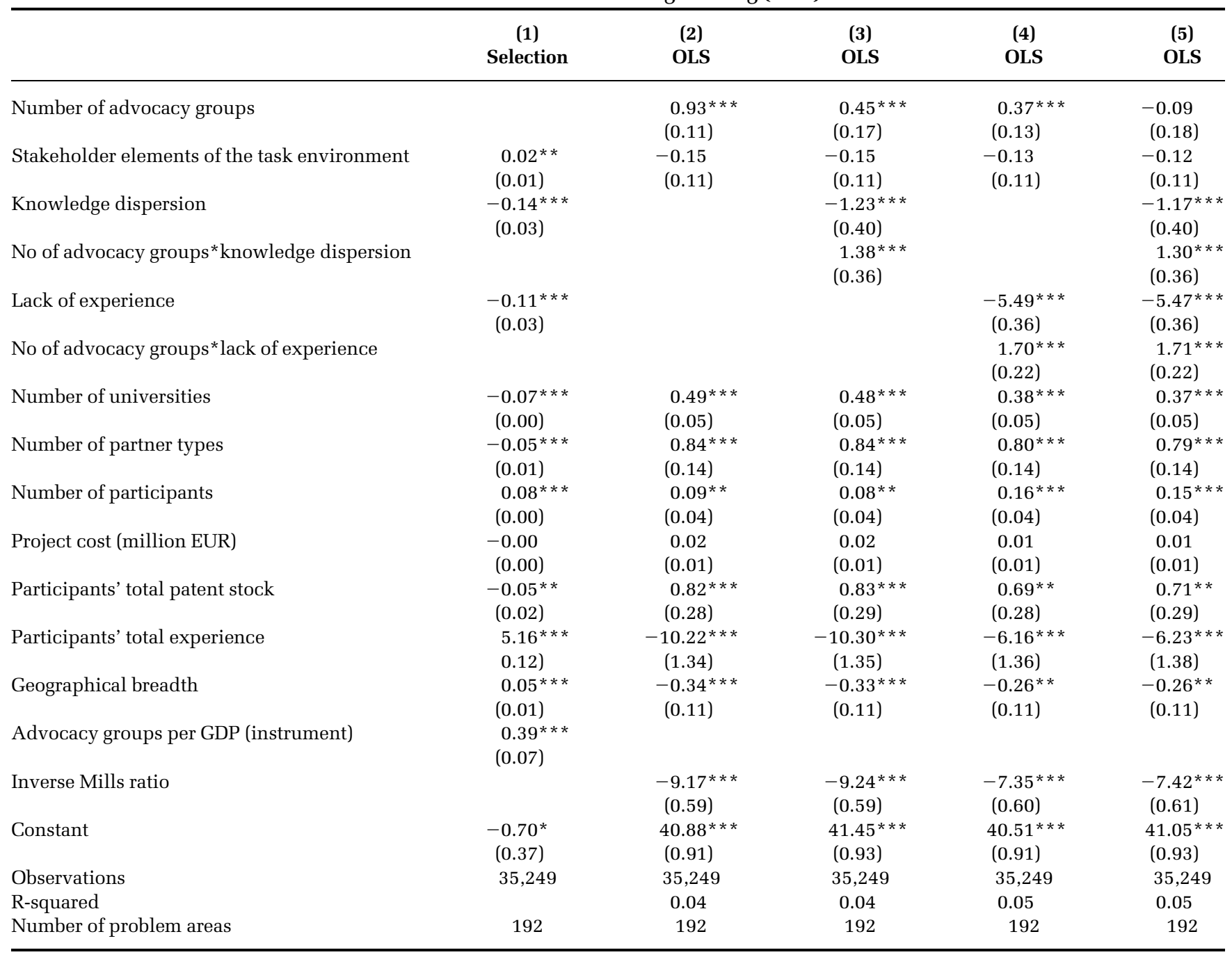

Notes: Robust standard errors in parentheses. ${ }^{* * *} p<0.01,{ }^{* *} p<0.05,{ }^{*} p<0.1$.

possess a deep understanding of stakeholder concerns, their involvement helps identify areas of the search space that contain solutions which are acceptable to them. These solutions are unlikely to face resistance, protests, or political intervention (Harrison and St. John, 1996). Second, advocacy group involvement legitimizes organizational search vis-à-vis an evaluating body. A search consortium can borrow from an advocacy group's legitimacy to signal that a proposed solution reflects the interests of relevant stakeholders and that these interests will be preserved once resources have been allocated (Baum and Oliver, 1991; Bitektine, 2011).

Both mechanisms are difficult to disentangle empirically. Therefore, we study two conditions under which one mechanism is likely to dominate. We suggest that the first mechanism is more important when search consortia have increasingly dispersed technological knowledge and that the second dominates when search consortia are inexperienced. In fact, we find the positive effects of advocacy involvement to be particularly strong when the dispersion of technology in a consortium is high. In that sense, while prior literature has identified communication among specialists (e.g., Brown and Eisenhardt, 1995) or certain skill profiles of those specialists (e.g., Iansiti, 1995; Madhavan and Grover, 1998) as mechanisms to achieve coordination, we identify advocacy group involvement as a mechanism to facilitate coordination in a search consortium. 
Moreover, a search consortium benefits more from legitimacy when it lacks experience. In that sense, advocacy group involvement can help new consortia to overcome an inherent challenge, i.e., gaining experience with a given evaluating body. While advocacy groups cannot immediately alleviate such liabilities of newness, they can mitigate the negative effects.

Our research makes several contributions to the literature. First, our theoretical model integrates prior theory on organizational search with stakeholder theory (Freeman, 1984; Freeman et al., 2010) to acknowledge the importance of stakeholder acceptance or support for any proposed solution. Extant research on joint search assumes that all organizations in a search consortium search for solutions within their particular domain (Knudsen and Srikanth, 2014; Puranam and Swamy, 2016). We highlight that certain organizations involved in coordinated exploration may help alleviate coordination problems although they do not necessarily possess deep expertise in a certain technological domain. We also find that the likelihood of receiving funding increases when search consortia can legitimize their approach to explore the search space. The legitimacy of organizations engaged in search, in particular, and its social construction has received virtually no attention in the theoretical and empirical literature on organizational search. This becomes all the more important as organizations need to secure resources in order to be able to implement a particular search approach. As a consequence, studies which focus exclusively on contributions to joint search efforts based on technological expertise (e.g., using patent applications or scientific publications) may systematically underestimate the contribution of partners with coordinating or legitimizing functions, i.e., they are likely to be biased.

Second, by integrating stakeholder theory into a model of joint search, we model advocacy groups as active partners in shaping the search for solutions to grand challenges. We add to the scarce literature on innovative outcomes from advocacy group interaction with other organizations (Harting et al., 2006). Our theorizing is not focused on avoiding protests, resistance, or political intervention (Harrison and St. John, 1996) but rather on the innovative potentials that result from advocacy group involvement. Following our contingency approach, we find that potentials are particularly high for search consortia with widely dispersed technological knowledge and without experience.

Third, our research allows a closer look at advocacy groups in the context of organizational search in two ways. Investigating the conditions under which advocacy groups are more likely to be involved in organizational search, we add to the stream of research that attempts to identify when stakeholders become salient to an organization (e.g., Mitchell et al., 1997; Christmann, 2004; Eesley and Lenox, 2006). We show that task environments are heterogeneous in the degree to which they require the acceptance or support of stakeholders and that these stakeholder elements increase the likelihood that search consortia will establish a relationship with advocacy groups. This extends models of coordinated exploration in which the institutional composition of organizations is implicitly assumed to be exogenous (Knudsen and Srikanth, 2014; Puranam and Swamy, 2016).

Moreover, our reasoning is consistent with instrumental stakeholder theory, which predicts that stakeholders' contribution to an organization's success corresponds with the gains that stakeholders can expect from such commitment (Harrison et al., 2010). Advocacy groups have an obvious interest in organizations performing research that advances solutions to problems that those groups are concerned with. They will, however, not contribute to such efforts if they believe that the involvement in a consortium may jeopardize their brand and reputation because the eventual outcome could be adversarial to their stakeholders' interests.

Finally, our research can provide guidance to governments and foundations in charge of grand challenge funding instruments as well as to organizations, including advocacy groups, which form consortia to search for solutions. For the former, we find evidence that the formation of search consortia is sensitive to the formulation of a grand challenge since it triggers important selection mechanisms for advocacy groups. For the latter, our findings show the benefits from the involvement and interaction with stakeholders represented by advocacy groups. Particularly, search consortia in which technology is highly dispersed and that are inexperienced have a lot to gain from cultivating relationships with advocacy groups. Similarly, advocacy groups have significant incentives to engage actively and systematically with other organizations, for example, firms or universities, for solving grand challenges in their stakeholders' interests.

\section{CONCLUSION}

Our research is not without limitations, which provide promising pathways for further research. First, while we observe the evaluation that independent experts assign to an application, we do not have 
information on whether or not the consortium eventually succeeded in finding a solution to a concrete problem. It would be desirable to mirror the likelihood to receive funding with the actual outcome from an approach to explore the search space using ex-post measures and controlling for exogenous factors. Second, we deploy several techniques for investigating potential endogeneity of the inclusion of advocacy groups and find no biases on the theorized relationships. Ideally, we would have liked to observe an exogenous shock creating a natural experiment. This does not occur during our observation period. Future studies may be able to develop research designs in similar contexts, i.e., consortia grant applications within grand challenges, including such exogenous shocks and thereby substantiating our findings.

Third, our qualitative interviews with experts hint at potential frictions and the need to manage interactions with advocacy groups. While the number of consortia with multiple advocacy groups in our sample is rather small, different advocacy groups may compete to promote their individual agendas, thereby complicating coordination and the definition of a joint approach to explore the search space. Furthermore, certain characteristics of advocacy groups such as size, power, or public attention, which we cannot take into account systematically, may influence their behavior in search consortia. Relatedly, some interview respondents emphasize the particular network positions that advocacy groups possess, which facilitate the flow of information or legitimacy. Dedicated studies drawing on network theory and data may find a fruitful path for identifying further heterogeneity among advocacy groups. In sum, there is much to be gained from a more fine-grained understanding of the micro-mechanisms underlying our results.

\section{REFERENCES}

Aldrich, H. E., \& Fiol, C. M. 1994. Fools rush in? The institutional context of industry creation. Academy of Management Review, 19: 645-670.

Anderson, P. 1999. Perspective: Complexity theory and organization science. Organization Science, 10: 216-232.

Azoulay, P., Graff Zivin, J. S., \& Wang, J. 2010. Superstar extinction. The Quarterly Journal of Economics, 125: 549-589.

Bascle, G. 2008. Controlling for endogeneity with instrumental variables in strategic management research. Strategic Organization, 6: 285-327.
Baum, J. A. C., \& Oliver, C. 1991. Institutional linkages and organizational mortality. Administrative Science Quarterly, 36: 187-218.

Belsley, D. A., Kuh, E., \& Welsh, R. E. 1980. Regression diagnostics: Identifying influential data and sources of collinearity. New York: Wiley.

Bitektine, A. 2011. Toward a theory of social judgements of organizations: The case of legitimacy, reputation, and status. Academy of Management Review, 36: 151-179.

Boeker, W. 1989. The development and institutionalization of subunit power in organizations. Administrative Science Quarterly, 34: 388-410.

Bosse, D. A., \& Coughlan, R. - forthcoming. Stakeholder relationship bonds. Journal of Management Studies.

Boudreau, K. J., Guinan, E. C., Lakhani, K. R., \& Riedl, C. 2016. Looking across and looking beyond the knowledge frontier: Intellectual distance, novelty, and resource allocation in science. Management Science. Published online ahead of print. doi: 10.1287/mnsc.2015.2285.

Brown, S. L., \& Eisenhardt, K. M. 1995. Product development: Past research, present findings, and future directions. Academy of Management Review, 20: 343-378.

Certo, S. T. 2003. Influencing initial public offering investors with prestige: Signaling with board structures. Academy of Management Review, 28: 432-446.

Certo, S. T., Busenbark, J. R., Woo, H.-S., \& Semadeni, M. forthcoming. Sample selection bias and Heckman models in strategic management research. Strategic Management Journal.

Choi, Y. R., \& Shepherd, D. A. 2005. Stakeholder perceptions of age and other dimensions of newness. Journal of Management, 31: 573-596.

Christmann, P. 2004. Mutlinational companies and the natural environment: Determinants of global environmental policy standardization. Academy of Management Journal, 47: 747-760.

Clarkson, M. B. E. 1995. A stakeholder framework for analyzing and evaluating corporate social performance. Academy of Management Review, 20: 92-117.

Cohen, W. M., \& Levinthal, D. A. 1990. Absorptive capacity: A new perspective on learning and innovation. Administrative Science Quarterly, 35: 128-152.

Collins, P. Y., et al. 2011. Grand challenges in global mental health. Nature, 475: 27-30.

Colquitt, J. A., \& George, G. 2011. Publishing in AMJ-Part 1: Topic choice. Academy of Management Journal, 54: 432-435.

Connelly, B. L., Certo, S. T., Ireland, R. D., \& Reutzel, C. R. 2011. Signaling theory: A review and assessment. Journal of Management, 37: 39-67. 
Criscuolo, P., Dahlander, L., Grohsjean, T., \& Salter, A. 2016. Evaluating novelty: The role of panels in the selection of R\&D projects. Academy of Management Journal. Published online ahead of print. doi: 10.5465/ amj.2014.0861.

Davis, J. P., \& Eisenhardt, K. M. 2011. Rotating leadership and collaborative innovation: Recombination processes in symbiotic relationships. Administrative Science Quarterly, 56: 159-201.

Deephouse, D. L. 1999. To be different, or to be the same? It's a question (and theory) of strategic balance. Strategic Management Journal, 20: 147-166.

Dodgson, M., Gann, D., Wladawsky-Berger, I., Sultan, N., \& George, G. 2015. Managing digital money. Academy of Management Journal, 58: 325-333.

Drees, J. M., \& Heugens, P. P. M. A. R. 2013. Synthesizing and extending resource dependence theory: A metaanalysis. Journal of Management, 39: 1666-1698.

Duriau, V. J., Reger, R. K., \& Pfarrer, M. D. 2007. A content analysis of the content analysis literature in organization studies: Research themes, data sources, and methodological refinements. Organizational Research Methods, 10: 5-34.

Eesley, C., \& Lenox, M. J. 2006. Firm responses to secondary stakeholder action. Strategic Management Journal, 27: 765-781.

European Commission 2007. FP7 in brief: How to get involved in the $\mathrm{EU}$ 7th Framework Programme for Research. Brussels: European Commission.

Flammer, C., \& Kacperczyk, A. J. 2016. The impact of stakeholder orientation on innovation: Evidence from a natural experiment. Management Science, 62: 1982-2001.

Freeman, R. E. 1984. Strategic management: A stakeholder approach. Boston: Pitman.

Freeman, R. E., Harrison, J. S., Wicks, A. C., Parmar, B., \& de Colle, S. 2010. Stakeholder theory: The state of the art. Cambridge: Cambridge University Press.

Frooman, J. 1999. Stakeholder influence strategies. Academy of Management Review, 24: 191-205.

Gavetti, G., \& Levinthal, D. 2000. Looking forward and looking backward: Cognitive and experiential search. Administrative Science Quarterly, 45: 113-137.

George, G., Haas, M. R., \& Pentland, A. 2014. Big data and management. Academy of Management Journal, 57: 321-326.

Godfray, H. C., Pretty, J., Thomas, S. M., Warham, E. J., \& Beddington, J. R. 2011. Global food supply: Linking policy on climate and food. Science, 331: 1013-1014.

Grand Challenges Canada 2016. Who we are; http://www. grandchallenges.ca/who-we-are/; January 4, 2016.
Hamilton, B. H., \& Nickerson, J. A. 2003. Correcting for endogeneity in strategic management research. Strategic Organization, 1: 51-78.

Hannan, M. T., \& Freeman, J. 1989. Organizational ecology. Cambridge, MA: Harvard University Press.

Harrison, J. S., \& St. John, C. H. 1996. Managing and partnering with external stakeholders. The Academy of Management Executive, 10: 46-60.

Harrison, J. S., Bosse, D. A., \& Phillips, R. A. 2010. Managing for stakeholders, stakeholder utility functions, and competitive advantage. Strategic Management Journal, 31: 58-74.

Harting, T. R., Harmeling, S. S., \& Venkataraman, S. 2006. Innovative stakeholder relations: When "ethics pays" (and when it doesn't). Business Ethics Quarterly, 16: 43-68.

Heugens, P. P. M. A. R., van den Bosch, F. A. J., \& van Riel, C. B. M. 2002. Stakeholder integration: Building mutually enforcing relationships. Business \& Society, 41: 36-60.

Howard-Grenville, J., Buckle, S. J., Hoskins, B. J., \& George, G. 2014. Climate change and management. Academy of Management Journal, 57: 615-623.

Hummels, D., Jørgensen, R., Munch, J., \& Xiang, C. 2014. The wage effects of offshoring: Evidence from Danish matched worker-firm data. The American Economic Review, 104: 1597-1629.

Iacus, S. M., King, G., \& Porro, G. 2011. Causal inference without balance checking: Coarsened exact matching. Political Analysis, 20: 1-24.

Iansiti, M. 1995. Technology integration: Managing technological evolution in a complex environment. Research Policy, 24: 521-542.

Innovative Medicines Initiative 2009. PROactive: Physical activity as a crucial patient reported outcome in COPD. https://www.imi.europa.eu/sites/default/files/uploads/ projects/documents/factsheets/imi-1st-call-factsheetsproactive_en.pdf.

Jaffe, A. B. 1986. Technological opportunity and spillovers of R \& D: Evidence from firms' patents, profits, and market value. The American Economic Review, 76: 984-1001.

Jones, T. M. 1995. Instrumental stakeholder theory: A synthesis of ethics and economics. Academy of Management Review, 20: 404-437.

Knudsen, T., \& Levinthal, D. A. 2007. Two faces of search: Alternative generation and alternative evaluation. Organization Science, 18: 39-54.

Knudsen, T., \& Srikanth, K. 2014. Coordinated exploration: Organizing joint search by multiple specialists to overcome mutual confusion and joint myopia. Administrative Science Quarterly, 59: 409-441.

Kotha, R., George, G. A., \& Srikanth, K. 2013. Bridging the mutual knowledge gap: Coordination and the 
commercialization of university science. Academy of Management Journal, 56: 498-524.

Krippendorff, K. 2004. Content analysis: An introduction to its methodology (2nd edn). Thousand Oaks, CA: Sage.

Lawrence, P. R., \& Lorsch, J. W. 1967. Differentiation and integration in complex organizations. Administrative Science Quarterly, 12: 1-47.

Liu, J., et al. 2015. Sustainability. Systems integration for global sustainability. Science, 347: 1258832.

Lounamaa, P. H., \& March, J. G. 1987. Adaptive coordination of a learning team. Management Science, 33: 107-123.

Love, J. H., Roper, S., \& Vahter, P. 2014. Learning from openness: The dynamics of breadth in external innovation linkages. Strategic Management Journal, 35: 1703-1716.

Madhavan, R., \& Grover, R. 1998. From embedded knowledge to embodied knowledge: New product development as knowledge management. Journal of Marketing, 62: 1-12.

Mitchell, R. K., Agle, B. R., \& Wood, D. J. 1997. Toward a theory of stakeholder identification and salience: Defining the principle of who and what really counts. Academy of Management Journal, 22: 853-886.

Nadkarni, S., \& Barr, P. S. 2008. Environmental context, managerial cognition, and strategic action: An integrated view. Strategic Management Journal, 29: 1395-1427.

Olsen, A. Ø., Sofka, W., \& Grimpe, C. 2016. Solving environmental problems: Knowledge and coordination in collaborative search. Long Range Planning. Published online ahead of print. doi: 10.1016/j.lrp.2016.05.003.

Omenn, G. S. 2006. Grand challenges and great opportunities in science, technology, and public policy. Science, 314: 1696-1704.

Piezunka, H., \& Dahlander, L. 2015. Distant search, narrow attention: How crowding alters organizations' filtering of suggestions in crowdsourcing. Academy of Management Journal, 58: 856-880.

Puranam, P., Raveendran, M., \& Knudsen, T. 2012. Organization design: The epistemic interdependence perspective. Academy of Management Review, 37: 419-440.

Puranam, P., \& Swamy, M. 2016. How initial representations shape coupled learning processes. Organization Science, 27: 323-335.

Ring, P. S., \& van de Ven, A. H. 1994. Developmental processes of cooperative interorganizational relationships. Academy of Management Review, 19: 90-118.

Rivkin, J. W., \& Siggelkow, N. 2003. Balancing search and stability: Interdependencies among elements of organizational design. Management Science, 49: 290-311.

Savage, G. T., Nix, T. H., Whitehead, C. J., \& Blair, J. D. 1991. Strategies for assessing and managing organizational stakeholders. The Academy of Management Executive, 5: 61-75.

Siggelkow, N., \& Rivkin, J. W. 2005. Speed and search: Designing organizations for turbulence and complexity. Organization Science, 16: 101-122.

Simon, H. A. 1962. The architecture of complexity. Proceedings of the American Philosophical Society, 106: 467-482.

Suchman, M. C. 1995. Managing legitimacy: strategic and institutional approaches. Academy of Management Review, 20: 571-610.

Terry, S. F., Terry, P. F., Rauen, K. A., Uitto, J., \& Bercovitch, L. G. 2007. Advocacy groups as research organizations: The PXE International example. Nature Reviews. Genetics, 8: 157-164.

Varmus, H., Klausner, R., Zerhouni, E., Acharya, T., Daar, A. S., \& Singer, P. A. 2003. Public health: Grand challenges in global health. Science, 302: 398-399.

Vergne, J.-P. 2012. Stigmatized categories and public disapproval of organizations: A mixed-methods study of the global arms industry, 1996-2007. Academy of Management Journal, 55: 1027-1052.

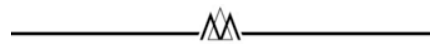

Anders Ørding Olsen (aoo.ino@cbs.dk) is an external lecturer at the Department of Innovation and Organizational Economics at Copenhagen Business School and a management consultant. He received a $\mathrm{PhD}$ in economics and management from Copenhagen Business School in 2016. His research and professional interests include firm strategy, innovation, and sustainability.

Wolfgang Sofka (ws.smg@cbs.dk) is an associate professor at the Department for Strategic Management and Globalization at Copenhagen Business School. He received a PhD from the University of Hamburg, Germany. His research interests encompass topics of knowledge search and appropriation in firm strategy as well as international business.

Christoph Grimpe (cg.ino@cbs.dk) is an associate professor at the Department of Innovation and Organizational Economics at Copenhagen Business School. He received a $\mathrm{PhD}$ from WHU-Otto Beisheim School of Management in Vallendar, Germany. His research focuses on various topics in firm strategy and innovation, including open innovation, intellectual property rights, and industryscience linkages.

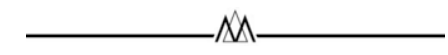




\section{APPENDIX 1}

\section{EXAMPLE PROBLEM DESCRIPTION IN CALL TEXT "COLLECTIVE AWARENESS PLATFORMS FOR SUSTAINABILITY AND SOCIAL INNOVATION" (ICT-2013.5.5)}

\section{Target Outcomes}

The objective is to stimulate and support the emergence of innovative ICT-based platforms for grassroots social innovation, providing societally, environmentally, and economically sustainable approaches and solutions to tackle societal challenges. Such collective intelligence platforms will include collective decision-making tools and innovation mechanisms allowing and encouraging individual and community creativity, participation, and situational awareness. The vision is that individuals and groups can more effectively and sustainably react to societal challenges by acting on the basis of a direct extended awareness of problems and possible solutions. To foster this, the objective has an experimental approach where concepts and tools are developed and verified in realworld cases. This will be achieved through the following set of complementary and interdependent actions:

(a) Supporting grassroots experiments and prototypes enabling citizens and communities to create and engage in digital social innovation platforms. These platforms should combine (i) open/federated social networking systems, (ii) cooperative creation and sharing of knowledge, and (iii) real-time gathering and management of information coming from people and their living environment (e.g. country, city, home). Possible applications could focus on sustainability (as understood in the wide sense defined above), in, for example, citizen empowerment, health, ageing and well being, inclusion, environment protection, direct democracy, sustainable lifestyles, and collaborative management of public goods. Open approaches, including free software, open hardware platforms, and open data infrastructures, are strongly encouraged.

(b) Support bottom-up social innovation and education initiatives based on crowd-sourcing and network intelligence principles, carried out by web innovators, research teams, communities, and entrepreneurs. The IP foreseen for this will select the activities to be funded through open calls, based on a combination of excellence (based on novelty and societal dimension of the actions proposed) and crowd funding mechanisms.

(c) Engaging citizens and society at large (coordination actions), aiming at:
- distilling the best practices from existing and new initiatives, creating synergies and critical mass, and targeting the integration of the various approaches to solve significant societal challenges;

- assessing the impact of the actions on communities allowing broad uptake of societal innovation, representing an empirical approach to the new topic of collective awareness platforms for sustainability and social innovation;

- achieving a multi stakeholder approach, helping social entrepreneurs get in touch with seed funding, for example, through venture capital networks or crowd-sourcing platforms;

- broadening the societal debate about the ethical aspects of societal sustainability, for example, on the fundamental rights of the citizens resulting from the digital transition, in terms of quality guarantees from collective systems;

- linking the existing and emerging initiatives with regulatory and policy activities on privacy and identity, open data, network neutrality, competitiveness, copyright, and alike, to be able to suggest sustainable approaches based on collective awareness.

(d) Integrating the scientific base for the multidisciplinary understanding of collective awareness platforms for sustainability and social innovation, addressing innovative mechanisms for value creation beyond monetization, reputation, motivation and incentives for online collaboration and sustainable collective behaviors, innovative licensing, open government, new forms of "selfregulation" based on individual situational and contextual awareness of global social constraints, self-configuration of communities.

\section{Expected Impact}

The overall expected impact is the emergence and takeup of new sustainable organizational and behavioral models at individual and community levels, resulting in sustainable social and economical innovation improving the quality of response to societal and economic challenges, such as growth, employment, inclusion, education, community development, health, environment, energy, and quality of life at large. Specific impacts are:

- Catalyzing and enabling new production and consumption patterns, lifestyles, and socio-economic processes based on commons, sharing, exchange, and participation at local and global scales.

- Definition of new concrete mechanisms increasing society's resilience, enabled by a more accurate 
understanding and management of social and environmental problems.

- Strengthened evidence of social innovation based on collective knowledge, which can also make possible new forms of foresight in society (by public bodies, organizations as well as by citizens).

- Providing advanced concepts and tools enabling people and communities to share, collaborate, and make use of data/information generated, empowering future social entrepreneurs, and innovators to engage in innovative service creation and delivery.

- Contributing to the emergence of new forms of political expression, "self regulation," innovative business and economic models, and social entrepreneurship.

\section{Challenge 5: ICT for Health, Ageing Well, Inclusion and Governance}

Challenge 5 builds on the previous research activities on health, ageing, inclusion, and governance. Nevertheless, it adapts to support new policy developments such as the Digital Agenda for Europe, the European Innovation Partnership on Active and Healthy Ageing and Horizon 2020. It adapts also to better support innovation and activities closer to the market like pre-commercial procurement actions and platforms supporting social innovation. The focus will be on development of solutions that empower the individual, in a social context, to improve and manage personal life as a citizen, in old age, patient, consumer, civil servant, or worker. Special emphasis will be given to productivity gains, customer satisfaction, and provision of new capabilities of public interest, in particular harnessing the "network effect" typical of ICT networks.

The "ICT for Health activities" will address the "health management" continuum from lifestyle to disease management, including disease prevention and management of comorbidities. This will be complemented by the research in the computational modeling of human physiology, paving the way for the next generation of healthcare services to enable patient empowerment and safer, more personalized care.

The "ICT for Ageing and Independent Living" activities will focus on empowering people with age-related dependencies or disabilities to live independently, delay/ avoid institutionalization, and to stay active as much and as long as possible. Solutions may combine health, social care, and smart living systems and 'age-friendly' environments. This will be implemented jointly with ICT for Health activities in direct support of activities defined under the EIP Active and Healthy Ageing. Social and service robotics and early prediction will not be reopened in this call.

"ICT for smart and personalized inclusion" will focus on the development of accessible solutions for personalized interfaces to smart environments and innovative services for all users including those at risk of exclusion (disability, low digital literacy/e-skills). These activities will be complemented by coordination activities on roadmapping on advanced human interactions for accessibility, market strategy for eInclusion services, and harmonization of accessibility strategies.

Research in "ICT for Governance and Policy Modeling" will address collaborative governance supported by ICT tools empowering citizen and increasing transparency in decision making. In particular, research will address the social and economic exclusion of the younger generation, policy modeling for productivity gains and innovation in public service provision and for identifying emerging societal trends. Finally, a new activity will support collaborative, collective awareness ICT platforms for grassroots social innovation towards a more sustainable future. The scheme will support application-specific platforms enabling experiments and prototypes of decentralized grassroots social innovation for collective actions and improvement of societal aspects of human activities as well as related scientific and coordination issues.

\section{APPENDIX 2}

\section{EXAMPLE PROBLEM DESCRIPTION IN CALL TEXT "CO-MORBIDITY BETWEEN INFECTIOUS AND NON-COMMUNICABLE DISEASES” (HEALTH.2012.2.3.2-2)}

Increasing evidence suggests that pathologies of many infectious diseases can be strongly influenced by concurrent presence in the same individual of non-infectious diseases, or vice-versa. The objective of this topic is to support basic, translational, and/or clinical research with the aim of improving basic knowledge, disease prevention, therapeutic management, and prognosis of patients with both infectious and non-communicable diseases. The proposals are expected to elucidate and clarify causative links between infectious and non-communicable diseases, and may also address diagnosis, or investigator driven clinical trials on treatments of particular relevance for patients with co-morbidities. The proposals should address combination(s) of any of the three major poverty-related diseases (HIV/AIDS, malaria, or tuberculosis) or any of the neglected infectious diseases with non-infectious diseases of major importance, such as, but not limited to, rheumatic or cardiovascular diseases, cancer, or diabetes.

Funding scheme: Collaborative project (small or mediumscale focused research project)

Expected impact: The successful projects will increase our knowledge of the causative links between infectious and noncommunicable diseases and will contribute to better prevention, treatment, and management of patients suffering from such co-morbidities. The expected impact includes optimized treatment, reduced mortality, and ameliorated quality of life of patients. The selected projects need to demonstrate that collaboration between different disease areas can significantly strengthen and integrate the health systems. 


\section{Translating Research for Human Health}

This activity aims at increasing knowledge of biological processes and mechanisms involved in normal health and in specific disease situations, to transpose this knowledge into clinical applications including disease control and treatment, and to ensure that clinical (including epidemiological) data guide further research.

\section{Translational Research in Major Infectious Deceases: To Confront Major Threats to Public Health}

The aim of this area is to confront major threats to public health with emphasis on HIV/AIDS, malaria, tuberculosis, hepatitis, neglected infectious diseases, emerging epidemics, and antimicrobial drug resistance, including fungal pathogens.

\section{HIV/AIDS, malaria and tuberculosis}

The focus will be on promoting translational research aiming at bringing basic knowledge through to clinical application in developing new therapies, diagnostic tools, and vaccines for HIV/AIDS, malaria, and tuberculosis. Research efforts will confront the three diseases at the global level, but will also address specific European aspects. The objective is to create a European research environment, where highly innovative ideas are conceived and new approaches to prevention, treatment, diagnosis, and management of the diseases can be developed. For this call for proposals, topics focus on co-infection and comorbidity, as well as on prevention and treatment of HIV/ AIDS, malaria, and tuberculosis.

\section{APPENDIX 3}

\section{DICTIONARY CREATION AND VALIDATION}

Content analyses in management research have been applied in various ways and to different types of text. They have recently been used for example to capture the public disapproval of organizations based on media reports (Vergne, 2012) or managerial cognition based on letters to shareholders (Nadkarni and Barr, 2008). Call texts are a fitting source for applying content analysis since the texts emerge through identical, multilayered processes at the European Commission. Expert advisory groups identify needs for work programs. The European Commission circulates these work programs internally, consults with its dedicated administrative units (Directorates-General), and creates draft calls. These drafts enter program committees with representatives from all 28 member states which have the opportunity to ask for changes. The resulting call text is therefore very precisely worded with regard to its particular scope and intended outcomes.

We follow the protocol of Vergne (2012) to achieve reliability and validity. For the former, we rely consistently on multiple experts and raters. For the latter, we conduct a whole range of expert interviews with FP7 call writers, interpreters (advisors or consultants), and regular call readers to ensure that the content analysis of FP7 call texts is indicative of elements related to stakeholder acceptance or support (Duriau et al., 2007). Our protocol has three major steps in which we iteratively improve the dictionary to increase reliability and validity:

1. We conduct 13 expert interviews with representatives from the European Commission (call writers), national contact points, and grant advisors (call interpreters) as well as call applicants (call readers). Based on these interviews, we clarify application procedures and identify relevant components of call texts as well as formulations which would indicate the elements related to stakeholder acceptance or support within a given call text. Based on these insights, we review calls and create an initial list of words (and short phrases) for the dictionary.

2. We discuss this preliminary dictionary with another group of nine experts who have significant experience in reading and interpreting calls from the European Commission (grant writers, grant consultants, experienced grant applicants). We ask those experts to remove words with below average chances of appearing in call texts emphasizing the need for stakeholder acceptance and support and add words which are missing. This process results in a dictionary of 66 words on which at least six experts agree (see Appendix 4). ${ }^{8}$ Examples of words include "civil society," "inclusive," "networking," "socioeconomic," or "transfer."

3. We use the resulting dictionary for elements related to stakeholder acceptance or support and calculate the fraction of words ${ }^{9}$ from the dictionary in each call text using the software tool LIWC. Separately, we ask two additional experts with experience in writing and evaluating grant proposals for the European Commission to read the entire problem-specific call text of a sub-sample of 30 call texts and to rate their prevalence for elements related to stakeholder acceptance or

\footnotetext{
${ }^{8}$ We experiment with broader or narrower word inclusion criteria. They produce call text classifications which are very similar. Correlations range from 0.92 to 0.94 .

${ }^{9}$ FP7 calls typically include standard components (such as the description of the overall Framework Program) and administrative rules (e.g., submission dates and processes). We focus the word count on the parts of the call text which are problem specific, mostly with the headlines scope, problem definition, and expected or targeted outcomes.
} 
support. The experts achieve high levels of intercoder reliability (Krippendorff, 2004) among one another $(\alpha 0.85)$ and with the fractional word count obtained using our dictionary ( $\alpha$ 0.81).
After those steps, we are confident that our dictionary for elements related to stakeholder acceptance or support in call texts generates a valid and reliable measure based on the fractional word count in the call texts.

\section{APPENDIX 4}

\section{DICTIONARY}

\begin{tabular}{|c|c|c|c|}
\hline NGO* & coordinat* $^{*}$ & inter-sectorial & secondment \\
\hline aggregated & cross-sectoral & interdisciplinary & shared \\
\hline association* & crossover & interest & social \\
\hline bridg* & dimension & joined & societ* \\
\hline bringing together & effect & leadership & societal challenge \\
\hline broad & effort & leverage & socio-economic* \\
\hline broad spectrum & entrepreneurial & linking & socioeconomic* \\
\hline broad-spectrum & entrepreneurship & multidisciplinary & stakeholder* \\
\hline capacity & exchange & networking & structural \\
\hline citizens & exploitation & participat* & target \\
\hline civil society & extensive & partner* & transfer* \\
\hline co-operation & grand & platform & wide \\
\hline collabor* & grand challenge & potential & \\
\hline combin* & impact & public & \\
\hline communic* & include & publication* & \\
\hline communit* & inclusive & publish & \\
\hline comprehensive & integrat* & relation & \\
\hline cooperat $^{*}$ & inter-sectoral & represent* & \\
\hline
\end{tabular}

Note: * denotes a placeholder for variations of word endings. 
Copyright of Academy of Management Journal is the property of Academy of Management and its content may not be copied or emailed to multiple sites or posted to a listserv without the copyright holder's express written permission. However, users may print, download, or email articles for individual use. 